it can present to the public in the way of supplying the requirements of a great teaching institution of university rank.

This College, in the first place, has complete Faculties of Arts, Laws, Science, and Medicine, and a School of Fine Arts, as well as a Boys' School. This College has fifty-eight professorial chairs in operation. In addition to the fifty-eight professors, there is a large teaching staft both on the general and on the medical side, - teachers, lecturers, demonstrators, and so on, -bringing up the whole members of the teaching staff to something like one hundred. Last session this College had between nineteen hundred and two thousand students. There were five bundred and fifty boys in the school. The buildings of this College, containing, as I have said, museums, libraries, lecture-halls, laboratories, and all the appliances of a university, are spread over seven acres. They cost $£ 300$,000 in construction. This College holds on trust no less a sum than $£ 200,000$, chiefly devoted to prizes, scholarships, and other objects of that kind; and it holds, besides, in trust a sum of $£ 135,000$ for hospital purposes. Its income is between $£ 33, \infty 00$ and $f 34,000$ a year. Taking, therefore, this College alone, so far as its buildings, the contents of its buildings, and its pecuniary resources are concerned, it stands on an equal footing with several of the universities in Great Britain ; and, taken in conjunction with King's College, it stands undoubtedly superior to some.

To this College, therefore, in combination with King's College, we may fairly look to the attainment of our object of establishing a Teaching University in London which will bring the higher education of London to the doors and within the pecuniary resources of the less wealthy classes of the metropolis, so that the disgrace that has hitherto attached to the metropolis of not affording a higher education, and the discredit that university education in England is to a very great extent a privilege of the wealthier and of the well-to do classes, may be wiped away. It should be within the reach of all, even of the student of the most humble means; and it would be well if this country were to take the example of Scotland in that respect, and to follow it. . .

In this new Teaching University there are two requirements that we insist upon. One is that the candidates for its degrees should have spent a certain specified time in attendance on lectures and instruction within its walls; and the other is that the examinations should be superintended and conducted by the teaching body of the University.

With regard to the first of these two points I wish to say a few words. . There is something more than mere knowledge that is acquired in academic instruction. There is a culture of mind and a development of the moral and social nature that cannot be acquired by solitary study; and it is for these reasons amongst others that those who are in favour of this movement are desirous that the candidates for the degrees of the new University should prosecute a portion, at all events, of their studies within the walls of the institution, so that they may imbibe something of the spirit, and that they may be in some way, too, impregnated by the genizus loci. This has been stigmatized as retrograde; but surely there can be nothing retrograde in that which has been found by universal experience to be the better system of education, and which is adopted in every teaching university in the country.

There is another point, and that is in regard to examinations, and it is a very essential point. We feel, and we feel very strongly indeed, that the examinations should not be directed by an outside body on which there are perhaps no examiners and no teachers, but that the examinations should be conducted by the teachers themselves in the institution in which the candidate learns. I do not say by the individual teacher of each class, but by the general body of the teachers, and that is a very different thing. And, as there would be more Colleges than one in the new Teaching University, a candidate need not in any way be examined by his own teacher, although he would be examined under the direction, superintendence, and control of the general body of the teachers. In every university now, I believe, throughout the Kingdom the teachers are assisted in their examination by assessors or by extra-professorial aid, whenever it is needed, and such, of course, would be the case in the new University. We feel that examinations ought not to lead teaching, and that if examinations are allowed to lead teaching, the teaching is fettered by the examination, and you get to a system of "cram"; the higher education and the higher teaching are apt to be neglected. I recollect many years ago a cir- cumstance illustrating this, occurring in this College in connexion with Prof. Sharpey, one of the mcst distinguished men ever connected with this College, the first Professor of Physiology here and, indeed, in London. There was no course, properly speaking, of Physiology given in London until Prof. Sharpey began his lectures here in the year $1836-37$. Prof. Sharpey gave an elaborate course of Physiology. From the commencement he attracted crowds of students. At that time there was connected with this College a most estimable and most amiable and most excellent old surgeon, who had grown grey within the walls, as it were, of the unreformed College of Surgeons, $\mathrm{Mr}$. Samuel Cooper. $\mathrm{He}$ was an examiner of the College of Surgeons, and I speak of him with the greatest respect; but he was never able to raise his mind beyond the requirements of the examinations of that institution. When he heard of what Prof. Sharpey was doing, he said, "What is the good of Sharpey teaching them all this kind of stuff? We do not want it at the College of Surgeons. We have never asked for it at the College of Surgeons. Why should he teach it to them ?" $\mathrm{He}$ had no conception beyond that, and that is the frame of mind that affects every mere examiner. He has a tendency to fetter and tie down the teaching to the level of his own examinations, and it is impossible to bring him or an examining institution above that level. We therefore wish that the instruction should lead the examination, and that the examination should follow in the wake of the teaching, and not the teaching in the wake of the examination.

\section{SCIENCE AND REVELATION.}

$\mathrm{N}$ the present anniversary, which is the conclusion of my first year of office as President of this Institute, I propose to address a few words to you bearing on the object of the Institute, and on the spirit in which, as I conceive, that object is best carried out.

The highest aim of physical science is, as far as may be possible, to refer observed phenomena to their proximate causes. I by no means say that this is the immediate, or even necessarily the ultimate object of every physical investigation. Sometimes our object is to investigate facts, or to co-ordinate known facts, and endeavour to discover empirical laws. These are useful as far as they go, and may ultimately lead to the formation of theories which in the end so stand the test of what I may call cross-examination by Nature, that we become impressed with the conviction of their truth. Sometimes our object is the determination of numerical constants, with a view, it may be, to the practical application of science to the wants of life.

To illustrate what $\mathrm{I}$ am saying, allow me to refer to a very familiar example. From the earliest ages men must have observed the heavenly bodies. The great bulk of those brilliant points with which at night the sky is spangled when clouds permit of their being seen, retain the same relative positions night after night and year after year. But a few among them are seen to change their places relatively to the rest and to one another. The fact of this change is embodied in the very name, planet, by which these bodies are designated. I shall say nothing here about the establishment of the Copernican system: I shall assume that as known and admitted. The careful observations of astronomers on the apparent places, from time to time, of these wandering bodies among the fixed stars supplied us, in the first instance, with a wide basis of isolated facts. After a vast amount of labour, Kepler at last succeeded in discovering the three famous laws which go by his name. Here, then, we have the second stage; the vast assemblage of isolated facts are coordinated, and embraced in a few simple laws. As yet, however, we cannot say that the idea of causation has entered in. But now Newton arises, and shows that the very same property of matter which causes an apple to fall to the earth, which causes our own bodies to press on the earth on which we stand, suffices to account for those laws which Kepler discovered-nay, more, those laws themselves are only very approximately true; and, when we consider the places of the planets, at times separated by a considerable interval, we are obliged to suppose that the elements of their orbits have slowly undergone slight changes. But the simple law of universal gravitation, combined, of course, with the laws of motion, not only leads to Kepler's laws as a very close approximation to the actual motions, but also accounts for those slight changes which have just been mentioned as

Presidential Address delivered by Prof. Stok P.R.S., at the annual meeting of the Victoria Institute, on Tuesday, July $\mathbf{r}$. 
necessary to make Kepler's laws fit observation exactly. We are inevitably led to regard the attraction of gravitation as the cause which keeps the planets in their orbits.

But it may be said, what is the difference in the two cases? Is not the law of gravitation merely a simpler mode of expressing the observed facts of the planetary motions just like the somewhat less simple laws of Kepler? What right have we to introduce the idea of causation in the one case more than in the other?

The answer to this appears to be that in the one case, that of Kepler's laws, supposing them to be true, we have merely a statement of what, on that supposition, would be a fact regarding the motions of the planets, whereas in the other case the observed motions are referred to a property of matter of the operation of which in other and perfectly different phenomena we have independent evidence.

I have purposely omitted to mention the important difference between the two cases, which lies in the circumstance that Kepler's laws require correction to make them applicable to long intervals of time, whereas the law of gravitation shows no sign of failure; because, even if the former had been perfectly exact, however long the interval of time to which they were applied, I doubt if they would have carried with them the idea of causation.

To take another simple illustration, let us think of the propulsion of a bullet in an air-gun. We speak of the motion of the bullet as being caused by the elasticity of the compressed air. And the idea of causation comes in because we refer this particular instance of motion to a property of gas, of the existence and operation of which we have evidence in perfectly independent phenomena.

It is thus that in scientific investigation we endeavour to ascend from observed phenomena to their proximate causes; but, when we have arrived at these, the question presents itself, can we in a similar manner regard these causes in turn as themselves the consequences of some cause stretching still further back in the chain of caltsation? If the motion of the bullet in an air.gun be caused by the elasticity of the compressed air, can we account for the elasticity of a gas? If the retention of the plancts in their orbits be due to the attraction of gravitation, can we explain how it is that two material bodies should attract one another across the intervening space?

Till a time well on in the present century, we could only take the elasticity of gases as a fact, and deduce the consequences which flow from it. But the researches of Joule and Clausius and Maxwell and Crookes and others have accumulated so much evidence in favour of the general truth of the kinetic theory of gases, that we are now disposed not to rest in the elasticity of gases as an ultimate property beyond which we cannot go, but to regard it as itself a consequence of the molecular constitution of bodies, and of the motions and mutual collisions of the ultimate molecules of a gas. Respecting the attraction of gravitation we have not at present made a similar advance. Speculations, indeed, have not been wanting on the part of those who have endeavoured to account for it. But none of these so fits into the known phenomena of Nature as to carry with it a conviction of its truth. Yet there is one indication that though we cannot at present explain the cause of gravitation, yet it may be explicable by what are called second causes. The mass of a body is measured by its inertia ; and, though we commonly think of a body of large mass as being heavy, and though we compare the masses of two bodies most easily and accurately through the intervention of weight, yet the idea of mass may be acquired, and means might easily be suggested by which the ratio of the masses of two bodies might be experimentally determined, without having recourse to gravitation at all. Now, according to the law of gravitation, the force with which a given body attracts another at a given distance is strictly proportional to the mass of the latter. If we suppose the attracting body to be the earth, and the attracted bodies to be in one case a brass weight, and in the other a piece of marble, it follows that if they make equilibrium when placed in the pans of a true balance-I make ab traction of the effect of the buoyancy of the air-their masses are strictly equal, and, accordingly, that weight is a true measure of mass. But there is no reason a priori, so far as with our present knowledge we can see, why this should be so. We know that if the bodies in the scale-pans were formed, one of brass and the other of iron, and there were a magnet concealed under the table on which the operator placed his balance, the masses would not be equal when there was equilibrium. But that the law is true, and that, accordingly, weight is a true measure of mass, follows with the highest probability from the third of Kepler's laws, and was proved experimentally by Newton, by experiments with pendulums. Newton's experiment has since been repeated by Bessel, with all the refinements of modern appliances, with the result that so far as the most exact experiments enable us to decide the law is strictly true. This is perhaps the only instance, as Sir William Thomson remarked to me in conversation, in which there is an exact agreement between two quantities, and yet we are unable to give any reason why they should agree. That such is the case, holds out some prospect of scientific men being able some day to explain gravitation itself - that is, to explain it as the result of some still higher law.

Such is the nature of our progress in scientific investigation. We collect facts; we endeavour to co-ordinate them and ascer tain the laws which bind them together; we endeavour to refer these laws to their proximate causes, and to proceed step by step upwards in the chain of causation. Presently we arrive at a stage at which, even after long trial, we do not see our way to going further. Yet we are not able to demonstrate that further progress in the same direction-that is, along the chain of secondary causation-is impossible. Science conducts us to a void which she cannot fill.

It is on other grounds that we are led to believe in a Being who is the Author of nature. A conclusion so important to mankind in general is not left to be established as the result of investigations which few have the leistre and ability to carry out. Doubtless, where it is accepted, the study of science enlarges our ideas respecting the greatness of that Being, and tends to keep in check notions of too anthropomorphic a character which we might form concerning Him. Still, the subject-matter of scientific study is not, at least directly, theistic, and there have not been wanting a few in-tances of eminent scientists who not merely rejected Christianity, but apparently did not even believe in the being of a God.

The religious man, on the other hand, who knows little or nothing of science, is in the habit of contemplating the order of Nature not merely as the work of God, but in very great measure as his direct work. Of course, the concerns of everyday life present innumerable instances of the sequence of cause and effect; and few are now so ignorant of the very elements of science as not to allow that the sequence of day and night, of summer and winter, is proximately due to the rotation of the earth about its axis, and the oblique position of that axis with re'erence to the plane of the earth's orbit. But when we get beyond the region of what is faniliarly known, still more when we get outside the limits of well-ascertained scientific conclusions, and enter a region which is still debatable ground, where men of science are attempting to push forwards, and are framing hypotheses with a view to the ultimate establishment of a theory in case those hypotheses should stand the test of thorough examination,- - when, I say, we get into this region, a man such as I have supposed may feel as if the scientists who were attempting to explore it were treading on holy ground; he may mentally charge them with irreverence; perhaps he may openly speak of them in a manner which implies that he attributes to them an intention to oppose revealed religion.

To take a particular example. I can imagine that a man such as I have supposed may have always been in the habit of regarding each one of the thousands and tens of thousands of species into which naturalists have divided the animal and vegetable kingdoms as having originated in an independent creative act; that the supposition may have become entwined among his religious beliefs. Such a man would be apprehensive of any attempt to introduce second causes in explanation of the observed fact of the great multiplicity of species.

Akin to the feeling which I have attempted to describe is another, against which we must be on our guard. The religious man is strongly impressed with the truth of certain things which lie outside the discoveries of reason or the investigations of science, and which bear on the whole conduct of his life here, and on his hopes regarding a life hereafter. He believes these truths to be divine, and, accordingly, that no legitimate deduction of human reason is liable to come in conflict with them. But the precise mode in which a conviction of the truth of these things was arrived at depends, to a considerable extent, on each man's idiosyncrasy. His natural bent of mind, his early training, his later associations, have all a good deal to do with it. Divine truth is one thing; our own apprehension of it, and the steps by 
which in our own minds it has been arrived at, are another. These are liable to human imperfection, and we may not attribute to them the infallibility which belongs to that which is divine. We are not to confound the scaffolding with the building; nor, if we are anxious for the safety of the edifice, need we therefore fear that, if the scaffolding were tampered with, the whole might come tumbling down, nor should we regard as a dynamiter a fellow wcrkman who would remove a pole or two.

That truth must be self-consistent, come from where it may, is an axiom which nobody would dispute; the only question can be, What is truth? Now, there are truths which we know by intuition, such as the axioms of mathematics; and there are others, again, which, though we do not perceive them by intuition, yet demonstrably follow from what we do so perceive such, for example, are the propositions of mathematics. Then there are other conclusions which we accept as the result of the application of our reason to a study of Nature. IHere the evidence is not demonstrative, and the conclusion may have all degrees of support, from such overwhelming evidence as that on which we accept universal gravitation, to what hardly raises the conclusion above the rank of a conjecture. On the other hand, there are conclusions which we accept on totally different grounds; namely, because we think that they have been revealed. Why we accept a revelation at all, is a very wide question which I cannot here enter into. That we do accept it is implied in the membership of this Institute. But, granting the acceptance of revelation, the question remains, What and how much is involved in revelation? That is a question respecting which there are differences of opinion among those who frankly accept a revelation, and with it the supernatural.

Now, the primary object of the establishment of the Victoria Institute was to examine the questions as to which there was a prime facie appearance of conflict between the conclusions of science and the teachings of revelation. In order that such examination may be usefully carried out, it must be undertaken in a thoroughly impartial spirit, with a readiness honestly to follow truth wherever it may lead. It will not do to assume that the immunity from error which belongs' to the divine belongs also to our apprehension of what constitutes the clivine, and that therefore, if a conflict there be, the error must be on the side of science. It is true, that many statements which are really little more than scientific conjectures are represented, at least by those who take their science at second or third hand, as if they were the well-established conclusions of science. But it is true also that the progress of science has corrected the assertions of a crude theology. We are disposed nowadays to smile at the idea of any opposition between the Copernican system and the teaching of revelation; but we need not go back to the days of the persecution of Galiles to find an example of a weli-supported scientific conclusion having met with a similar opposition, issuing in a similar result.

To gauge thoroughly the amount of evidence on which an asserted scientific conclusion rests, one ought to be well acquainted with the branch of science to which it relates. Still one can get a fair general notion of the evidence by an amount of reading which is by no means prohibitive, or by conversing with those who have made that branch a special study. It may be that the impression thus left on the mind will be that the votaries of science, carried away by an excess of zeal in the attempt to discover the causes of natural phenomena, have really, though honestly, overestimated the evidence. It may be, on the other hand, that the inquirer will perceive the evidence to be weighty and substantial, in which case it behoves him to reconsider the supposition with which he started, that the conclusion was opposed to the teaching of revelation.

One should always bear in mind the great responsibility one incurs, and the mischief one may do, by representing as bound up with revelation that which really forms no part of it. Being by hypothesis no part of it, but only erroneously tacked on to it, it may be false, and being false, it may be in opposition to a conclusion supported by the weightiest evidence, it matters not of what kind, but say scientific. What, then, will be the effect of the error committed by the upholder of revelation? The educated man of science may see through the fallacy; but will it not put a weapon into the hands of the infidel lecturer wherewith to attack revealed religion?

But whether we can agree or cannot agree with the conclusions at which the scientific investigator may have arrived, let us, above all things, beware of imputing evil motives to him ; of charging him with adopting his conclusions for the purpose of opposing what is revealed. Scientific investigation is eminently truthful. The investigator may be wrong, but it does not follow that he is other than truth-loving. If on some subjects which we deem of the highest importance he does not agree with usand yet it may be he agrees with us more than we suppose-let us, remembering our own imperfections, both of understanding and of practice, bear in mind that caution of the Apostle: "Who art thou that judgest another man's servant? To his own master he standeth or falleth."

\section{SCIENTIFIC SERIALS.}

Rendiconit dcl Reale Istituto Lombardo, June I6.--On the importance of the qualitative hacteriological examination of potable waters, by Prof. Leopoldo Maggi, Attention is directed to the mistake made by many chemists, who occupy themselves exclusively with the quantitative examination of potable waters, neglecting the much more important question of the specific quality of the germs, owing to the greater difficulty of distinguishing between the various forms of these organisms. Waters largely charged with harmless Bacteria are condemned, although perfectly drinkable, while others apparently pure, but really containing deadly germs in small quantity, are declared to be quite safe, often to the great danger of the public healh. It is in fact far more a question of quality than of quantity, as shown especially by the recent researches of Chantemesse and Vidal on the Bacillus of typhus. On the other hand, Leone has experimentally shown that comparatively pure water is itself a medium of culture, so that a small quantity of innocuous Bacteria may largely increase in it without rendering its use dangerous. Some instructions are added for distinguishing between harmless organisms normally present in water as their natural element, and pathological germs, which render it quite unfit for human consumption.-Meteorological observations made at the Brera Observatory, Milan, during the month of May.

\section{SOCIETIES AND ACADEMIES LONDON.}

Chemical Society, June I6.-Mr. William Crookes, F.R.S., President, in the chair. - The following papers were read:-A study of the thermal properties of a mixture of ethyl alcohol and ethyl oxide, by Dr. William Ramsay and Dr. Sydney Young.-Derivatives of bydrindonaphthene and tetrahydronaphthalene, by Dr. W. H. Perkin, Jun.-The synthetical formation of closed carbon chains in the aromatic series, by Dr. F. S. Kipping. - The product of the action of ethylene bromide on ethylic acetosodacetate, by Dr. P. C. Freer and Dr. W. H. Perkin, Jun.-The synthesis of hexamethylene-derivatives, by Dr. P. C. Freer and Dr. W. H. Perkin, Jun.-An attempt to synthetize heptamethylene-derivatives, by Dr. P. C. Freer and Dr. W. H. Perkin, Jun.-The composition of shale-spirit, by Dr. A. K. Miller and Mr. T. Baker. - The magnetic rotatory power of the ethyl salts of maleic and citraconic acids and their isomers, by Dr. W. II. Perkin, F.R.S.-The temperatures at which various sulphates undergo decomposition, by Dr. G. H. Bailey. - The reaction between sulphites and nitrites of metals other than potassium, by Dr. Edward Divers, F.R S., and Mr. Tamenasa Haga. - The action of acetyl chloride on acetoximes, by Mr. Victor Meyer and Mr. A. Warrington.-Sulphinic compounds of carbamide and thiocarbamide, by $\mathrm{Mr}$. George McGowan.-Anarcardic acid, by Dr. S. Ruhemann and Mr. S. Skinner.

\section{EDINBURGH}

Royal Society, July 4.-Mr. J. Murray, Vice-President, in the chair.-Prof. Tait communicated a paper by Mr. A. C. Mitchell on the thermal conductivity of iron, copper, and German silver. Mr. Mitcheil made his experiments upon the same bars as were used by Prof. Forbes and Prof. Tait, but the surfaces were nickelized so as to prevent oxidation. The results agree well with those of Prof. Tait, and are probably as correct as the method admits of.-Mr. T. B. Sprague read a paper on the probability that a marriage, entered into by a man of any 